\title{
Long-Term Treatment With Ranirestat (AS-3201), a Potent Aldose Reductase Inhibitor, Suppresses Diabetic Neuropathy and Cataract Formation in Rats
}

\author{
Takafumi Matsumoto ${ }^{1, *}$, Yoshiyuki Ono ${ }^{2}$, Akemi Kuromiya $^{3}$, Kaoru Toyosawa ${ }^{4}$, Yoshinaka Ueda ${ }^{4}$, \\ and Vera Bril ${ }^{5}$ \\ ${ }^{I}$ Pharmacology Research Laboratories, ${ }^{3}$ Genomic Science Laboratories, Dainippon Sumitomo Pharma Co., Ltd., \\ 1-98, Kasugade-naka 3-chome, Konohana-ku, Osaka 554-0022, Japan \\ ${ }^{2}$ International Business Management, Dainippon Sumitomo Pharma Co., Ltd., \\ 5-51, Ebie 1-chome, Fukushima-ku, Osaka 553-0001, Japan \\ ${ }^{4}$ Safety Research Laboratories, Dainippon Sumitomo Pharma Co., Ltd., Enoki 33-94, Suita, Osaka 564-0053, Japan \\ ${ }^{5}$ Department of Medicine, University of Toronto, EN11-209, Toronto General Hospital, \\ 200 Elizabeth St., Toronto, ON, M5G 2C4, Canada
}

Received March 13, 2008; Accepted May 26, 2008

\begin{abstract}
We investigated the chronic functional and histopathological changes in the sciatic nerve and lens of streptozotocin (STZ)-diabetic rats and evaluated the preventive effects of ranirestat (AS-3201), a potent aldose reductase inhibitor, on these changes. Sorbitol levels in the sciatic nerve and lens, motor nerve conduction velocity (MNCV), and development of cataracts were measured in STZ-diabetic rats given a ranirestat-admixed diet $(0.0005 \%)$ for 35 weeks. Ranirestat reduced sorbitol accumulation in the sciatic nerve and improved the decrease in MNCV of STZ-diabetic rats. Morphological and morphometric examination of changes in sural nerve revealed that treatment with ranirestat prevented both the deformity of myelinated fibers and the decrease in their axonal and myelin areas (atrophy). Ranirestat also averted the changes in the size frequency histogram of myelinated fibers. Finally, STZ-diabetic rats developed early lens opacities 8 weeks after STZ injection and had cataract by the end of the experimental period. However, in the ranirestat-treated diabetic rats, no lens opacity was observed in any rat throughout the entire experimental period. This study suggests that the polyol pathway plays an important role in the progress of diabetic neuropathy and cataract formation in STZ-diabetic rats. Ranirestat should be a promising agent for the treatment of complications associated with diabetes, especially neuropathy.
\end{abstract}

Keywords: ranirestat (AS-3201), diabetic neuropathy, cataract, aldose reductase inhibition

\section{Introduction}

The Diabetes Control and Complications Trial indicates that strict management of the blood glucose level is required to help prevent the progression of diabetic complications $(1,2)$. Nevertheless, even with the best clinical management available at present, it is practically impossible to maintain normoglycemia at all times.

*Corresponding author. takafumi-matsumoto@ds-pharma.co.jp Published online in J-STAGE on July 8, 2008 (in advance) doi: 10.1254 jphs.08071FP
Diabetic complications are caused by heterogeneous disorders arising from derangements of glucose metabolism, especially abnormalities in the polyol pathway. Activation of the polyol pathway under diabetic conditions may play an important role in the pathogenesis of various diabetic complications including neuropathy $(3-5)$, cataract formation $(6,7)$, retinopathy $(8,9)$, and nephropathy $(10,11)$. The polyol pathway involves the activation of two enzymes, aldose reductase (AR) and sorbitol dehydrogenase $(\mathrm{SH})$. AR, which is a ratelimiting enzyme of the polyol pathway, catalyzes the reduction of glucose to sorbitol. SH on the other hand catalyzes the oxidation of L-iditol to L-fructose using 


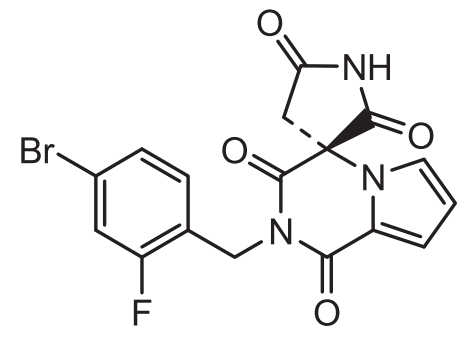

Fig. 1. Chemical structure of ranirestat $\left\{(3 R)-2^{\prime}-(4-b r o m o-2-\right.$ fluorobenzyl)spiro[pyrrolidine-3, 4' (1'H)-pyrrolo[1,2-a]pyrazine]$1^{\prime}, 2,3^{\prime}, 5\left(2^{\prime} H\right)$-tetrone\}.

$\mathrm{NHD}^{+}$as an electron acceptor.

Although a number of AR inhibitors such as epalrestat, zenarestat, and fidarestat have shown beneficial effects on diabetic complications in experimental animal models $(12-14)$, only epalrestat is available for the management of diabetic neuropathy in Japan. Ranirestat (AS-3201) (Fig. 1), a novel AR inhibitor developed in our laboratories and now in phase III clinical trials, appears promising in patients with diabetic sensorimotor polyneuropathy (15).

In the present study, the chronic functional and histopathological changes in the sciatic nerve and lens of streptozotocin (STZ) diabetic rats were investigated and the preventive effects of ranirestat on these changes were evaluated.

\section{Materials and Methods}

\section{Animals}

Male Crj:CD rats (SD; Charles River Japan, Inc., Yokohama) aged 8 weeks were maintained in an animal room with controlled temperature $\left(21^{\circ} \mathrm{C}-25^{\circ} \mathrm{C}\right)$ and humidity $(45 \%-65 \%)$ under a 12 -h light/dark cycle (light on 06:00 to 18:00). Rats had free access to standard food (MF; Oriental Yeast Industries, Ltd., Tokyo) and water. After 7 days of acclimation, the rats were made diabetic by the intravenous administration of streptozotocin (STZ, $60 \mathrm{mg} / \mathrm{kg}$; Sigma, St. Louis, MO, USA) dissolved in physiological saline containing $0.75 \mathrm{mM}$ citrate buffer $(\mathrm{pH} 4.5)$. One week after STZ injection, all STZ-treated rats were confirmed to be hyperglycemic (plasma glucose level $>300 \mathrm{mg} / \mathrm{dl}$ ).

The rats were then divided into 3 groups: 1 ) ranirestattreated diabetic group: rats were fed a $0.0005 \%$ ranirestat-admixed standard diet for 35 weeks (study period) starting 1 day after STZ injection, 2) diabetic control group: rats were fed the standard diet without ranirestat throughout the study period, and 3) nondiabetic control group: normal rats were fed the standard diet only.

Body weight, food consumption, and blood glucose level were measured once monthly. Blood glucose was measured with a glucose analyzer (Antosense; BayerSankyo, Tokyo) using samples drawn via the tail vein of non-fasted rats.

All experimental procedures were approved by the Institutional Animal Care and Use Committee of Dainippon Pharmaceutical Co., Ltd.

\section{Measurement of sorbitol levels in rat isolated sciatic nerve and lens}

Rats were anesthetized with sodium pentobarbital (50 mg/kg, i.p.; Abbott, Abbott Park, IL, USA), the sciatic nerve and lens were removed, promptly cooled with liquid nitrogen, and stored at $-50^{\circ} \mathrm{C}$. Sorbitol level in each tissue (sciatic nerve or lens) was measured by the method of Clements et al. (16). In brief, the sciatic nerves were heated in a 25 -fold sample volume (volume/weight) of distilled water at $100^{\circ} \mathrm{C}$ for $2 \mathrm{~min}$, and $6 \%$ perchloric acid $(0.1 \mathrm{ml} / \mathrm{mg}$ tissue $)$ was added. Nerve samples were then homogenized and centrifuged at 3,000 rpm for $10 \mathrm{~min}$. The supernatant was neutralized with $2 \mathrm{M}$ potassium carbonate, centrifuged again, and the resulting supernatant was used for sorbitol assay.

The lenses were homogenized in $6 \%$ perchloric acid $(0.05 \mathrm{ml} / \mathrm{mg}$ tissue $)$ and centrifuged at 3,000 rpm for $10 \mathrm{~min}$. The supernatant was neutralized with $2 \mathrm{M}$ potassium carbonate, centrifuged again, and the resulting supernatant was diluted with distilled water and used for sorbitol assay.

One milliter of extract from each tissue was mixed with $2 \mathrm{ml}$ glycine buffer $(0.05 \mathrm{M}, \mathrm{pH} 9.4)$ containing $2 \mathrm{mM}$ NAD and $0.05 \mathrm{ml} \mathrm{SDH}(25.6 \mathrm{U} / \mathrm{ml})$ and incubated at room temperature for $60 \mathrm{~min}$. After incubation, fluorescence of the generated NADH was measured at an excitation wavelength of $366 \mathrm{~nm}$ and emission wavelength of $452 \mathrm{~nm}$ using a spectrofluorometer (F-3000; Hitachi, Tokyo). Based on the difference in fluorescence intensity with or without addition of SDH, sorbitol levels in each extract were calculated from the calibration curve of reference D-sorbitol. Sorbitol contents in the sciatic nerve and lens were expressed as $\mu \mathrm{mol} / \mathrm{g}$ wet weight $(\mathrm{W} / \mathrm{W})$.

\section{Measurement of motor nerve conduction velocity (MNCV)}

MNCV in the rat sciatic nerve was measured using the method of Sharma et al. (17). Rats were restrained in a prone position and anesthetized by continuous inhalation of $2.5 \%$ halothane gas. A constant rectal temperature of $37.5^{\circ} \mathrm{C}-38.5^{\circ} \mathrm{C}$ was maintained by a temperature control system (ATB-1100; Nihon Kohden, Tokyo) right sciatic nerve was used as the proximal stimulus point (S1) and the ankle region of the right tibial nerve 
was used as the distal stimulus point (S2). An active needle electrode (negative) was inserted at each point (S1 and S2) and the reference electrode (positive) was inserted approximately $1 \mathrm{~cm}$ from $\mathrm{S} 1$ toward the spine. For recording, the active and reference electrodes were each inserted shallowly into the right plantar muscle. Using an induced potential detector (MEB-7202, Nihon Kohden), S1 and S2 were stimulated with single rectangular pulses (duration: $0.1 \mathrm{~ms}$; current: supramaximal, $1.0-4.2 \mathrm{~mA}$ ), and changes in the action potential were recorded. The proximal and distal latencies from stimulation of S1 and S2, respectively, to the rise of the action potentials ( $\mathrm{t} 1$ and $\mathrm{t} 2 \mathrm{in} \mathrm{ms}$ ), respectively, and the distance between $\mathrm{S} 1$ and $\mathrm{S} 2$ (d in $\mathrm{mm})$ were measured. MNCV was then calculated by the following equation: $\mathrm{MNCV}(\mathrm{m} / \mathrm{s})=\mathrm{d} /(\mathrm{t} 1-\mathrm{t} 2)$

\section{Cataract evaluation}

Opacities in both lenses were examined with a slit lamp according to the method of Ao et al. (18) after dilating the pupils with Mydrin P $(0.5 \%$ tropicamide and $0.5 \%$ phenylephrine; Santen Pharmaceutical, Osaka). The degree of lens opacity was given a score as follows: $0=$ clear normal lens, $1=$ slight opacity in the superficial cortical layers, and $2=$ diffuse central opacity. For each rat, the opacity scores for both lenses were summed. The sum of the scores was used as the total cataract score for both eyes $(0-4)$. The slit lamp examination was performed once every 2 months.

\section{Histopathological analysis of the sural nerve and eyeballs}

Under sodium pentobarbital anesthesia $(50 \mathrm{mg} / \mathrm{kg}$, i.p.; Abbott), the left eyeball was quickly removed and fixed in $10 \%$ formaldehyde $/ 2.5 \%$ glutaraldehyde. The abdomen of the rat was then opened and the vascular system was flushed by continuous infusion of ice-cold phosphate-buffered saline ( $\mathrm{pH} 7.4)$ via the abdominal aorta for $10 \mathrm{~min}$ under constant pressure. The vascular system was further perfused with Karnovsky fixative for 10 min. Next the sural nerve of the left hind limb was extirpated and fixed in ice-cold $2.5 \%$ glutaraldehyde for $3 \mathrm{~h}$.

The removed eyeball was embedded in paraffin, cut into thin sections (about $3 \mu \mathrm{m}$ ), and stained with hematoxylin-eosin. The perfusion-fixed sural nerve was post-fixed with $1 \%$ osmium tetroxide, embedded in Epon, cut into semi-ultrathin transverse sections (about $1 \mu \mathrm{m}$ ), and stained with toluidine blue. Both eyeball and sural nerve sections were examined under light microscopy. A quantitative morphometric analysis of the sural nerve was performed on 100 myelinated fibers/rat using an image analyzer (CIA-102; Olympus
Optical, Tokyo). As morphometric parameters of the myelinated fibers, the axonal area, myelin area, and circularity index (reciprocal of perimeter, i.e., degree of circumferential ruggedness) were determined. The sum of the myelin and axonal areas was calculated and designated as the myelinated fiber area. To obtain the size frequency distribution of the myelinated fibers, data from the measured area of 100 myelinated fibers/rat were classified into 13 sizes (from $0-10$ to $120-130$ $\mu \mathrm{m}^{2}$ ) using a unit size of $10 \mu \mathrm{m}^{2}$, and the frequency (\%) of the fibers in each size category was calculated.

\section{Statistical analyses}

Data values are each expressed as the mean \pm S.E.M. To ascertain that STZ caused diabetes in the rats, the F-test was used to confirm homogeneity of variance in sorbitol levels and morphological changes were compared between the non-diabetic control group and the Diabetic control group. Subsequently, Student's $t$ test was used to determine significance of difference. As for MNCV, it was measured only in the diabetic control group and Ranirestat-treated diabetic group. Student's $t$-test was used to determine significance of difference. A $P$ value less than 0.05 was considered statistically significant.

\section{Results}

Effects of ranirestat on body weight, food consumption, and blood glucose levels in STZ-diabetic rats

In the non-diabetic control rats, mean body weight increased from $238 \mathrm{~g}$ at the start of the experiment to $808 \mathrm{~g}$ at the end ( 35 weeks later). However, in the diabetic control rats, mean body weight increased gradually from $239 \mathrm{~g}$ before treatment with STZ to $363 \mathrm{~g}$ 6 weeks after STZ injection. The diabetic control rats then gained no further weight throughout the rest of the study period. In the ranirestat-treated diabetic rats, the time course of mean body weight changes was similar to that of the diabetic control rats with no difference between the two groups (Fig. 2). Mean food consumption was almost constant throughout the entire study period for all groups, about $30 \mathrm{~g} /$ day in the non-diabetic control rats, about $60 \mathrm{~g} /$ day in the STZ-diabetic control, and ranirestat-treated diabetic rats (Fig. 3).

Mean blood glucose levels in the non-diabetic control rats were constant at about $130 \mathrm{mg} / \mathrm{dl}$ throughout the experimental period. However, mean blood glucose levels in the diabetic control and ranirestat-treated diabetic rats were about $300 \mathrm{mg} / \mathrm{dl}$ one week after STZ injection. This hyperglycemia persisted until the end of the study period in both groups (Fig. 4). The mean ranirestat dose per rat in the ranirestat-treated diabetic 


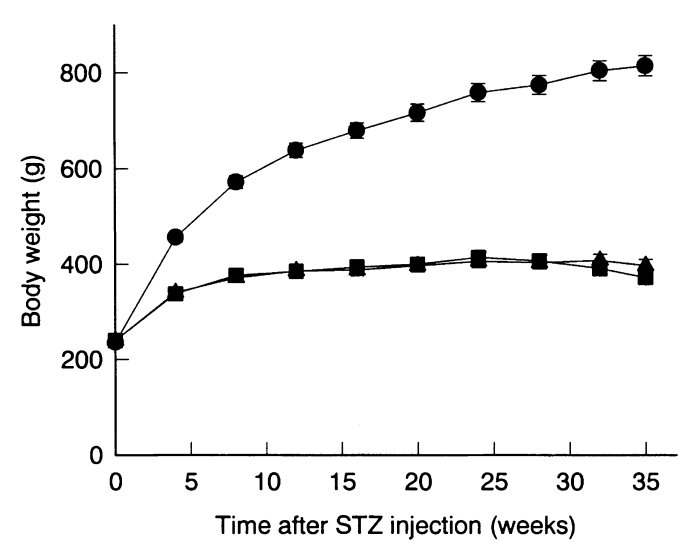

Fig. 2. Body weight change in the diabetic control (square), ranirestat-treated diabetic (triangle), and non-diabetic control (circle) rats. Each value indicates the mean \pm S.E.M. for 13 rats/group.

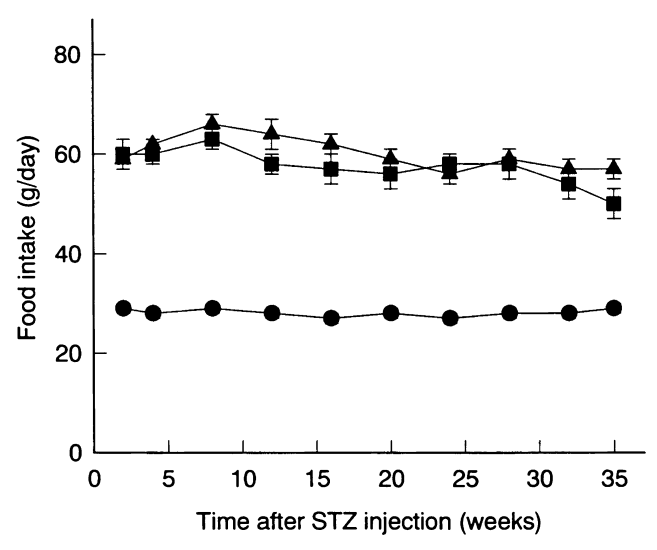

Fig. 3. Food consumption change in the diabetic control (square), ranirestat-treated diabetic (triangle), and non-diabetic control (circle) rats. Each value indicates the mean \pm S.E.M. for 13 rats/group.

group was about $0.8 \mathrm{mg} / \mathrm{kg}$ per day.

Two rats in the non-diabetic control group, 1 with hyperglycemia and the other with a tumor, were excluded from the data analysis. Also, 4 rats $(2$ in the diabetic control group and 2 in the ranirestat-treated diabetic group) succumbed to their diabetic condition and died.

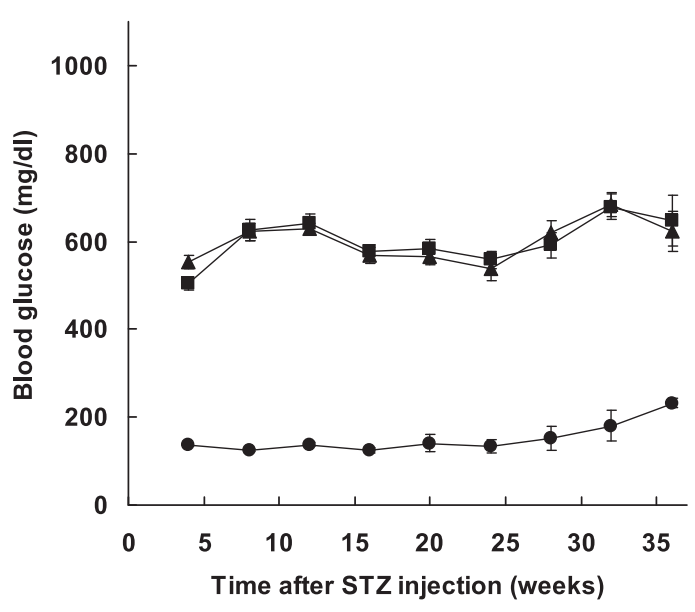

Fig. 4. Blood glucose change in the diabetic control (square), ranirestat-treated diabetic (triangle), and non-diabetic control (circle) rats. Each value indicates the mean \pm S.E.M. for 13 rats/group.

\section{Effects of ranirestat on sorbitol levels in the rat sciatic} nerve and lens

In the diabetic control rats, mean sorbitol levels in the sciatic nerve were significantly higher $(P<0.01)$ than the corresponding values in the non-diabetic control rats ( $2.98 \pm 0.22$ vs $0.24 \pm 0.02 \mu \mathrm{mol} / \mathrm{g}$ wet weight), but in the ranirestat-treated diabetic rats, mean sorbitol levels in the sciatic nerve were significantly lower $(P<0.01)$ than the corresponding value in the diabetic control rats $(0.11 \pm 0.01$ vs $2.98 \pm 0.22 \mu \mathrm{mol} / \mathrm{g}$ wet weight $)$. Sorbitol levels in the ranirestat-treated diabetic rats were of the same magnitude as those in the non-diabetic control animals. However, mean sorbitol levels in the lens of ranirestat-treated diabetic rats were only slightly lower than those in the diabetic control rats $(6.10 \pm 0.53$ vs $8.26 \pm 1.67 \mu \mathrm{mol} / \mathrm{g}$ wet weight, Table 1$)$.

\section{Effects of ranirestat on MNCV in rats}

The effects of ranirestat on MNCV in the rat sciatic nerve were evaluated after 35 weeks of treatment. As shown in Table 1 , the mean MNCV in the ranirestattreated diabetic rats was significantly higher than that in

Table 1. Effects of ranirestat on sorbitol content in the sciatic nerve and lens on MNCV in rats

\begin{tabular}{lccc}
\hline Group & \multicolumn{2}{c}{ Sorbitol $(\mu \mathrm{mol} / \mathrm{g}$ wet weight $)$} & $\begin{array}{c}\text { MNCV } \\
(\mathrm{m} / \mathrm{s})\end{array}$ \\
& Sciatic nerve & Lens & $41.2 \pm 0.4$ \\
Diabetic control & $2.98 \pm 0.22^{\text {\#\# }}$ & $8.26 \pm 1.67^{\# \#}$ & $45.0 \pm 0.4^{* *}$ \\
Ranirestat-treated diabetic & $0.11 \pm 0.01^{* *}$ & $6.10 \pm 0.53$ & - $^{\text {a) }}$ \\
Non-diabetic control & $0.24 \pm 0.02$ & $1.35 \pm 0.11$ & \\
\hline
\end{tabular}

${ }^{a} \mathrm{MNCV}$ in non-diabetic control rats was not measured. Each value represents the mean \pm S.E.M. for 13 rats/group. Comparison of two groups against the diabetic control group: ${ }^{*} P<0.01$ (Student's $t$-test). Comparison of two groups against the non-diabetic control group: ${ }^{\#} P<0.01$ (Student's $t$-test). 

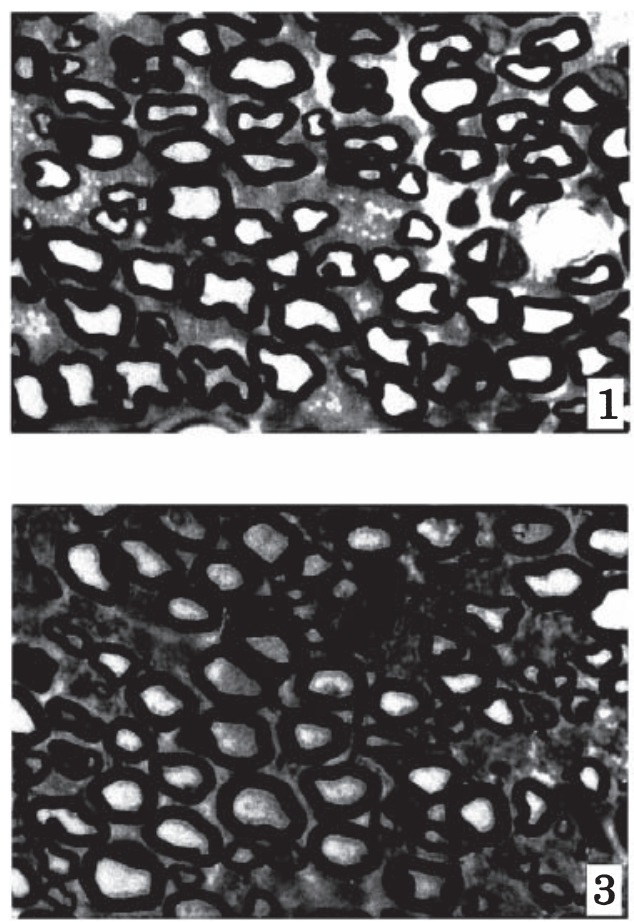

the diabetic control rats $(45.0 \pm 0.4 v s 41.2 \pm 0.4 \mathrm{~m} / \mathrm{s}$, $P<0.01)$.

\section{Morphological changes in the rat sural nerve fibers}

On the final day of the study period ( 35 weeks after induction of diabetes), the sural nerve was removed, and its transverse sections were histopathologically examined under light microscopy. In the non-diabetic control rats, the sural nerve contained almost exclusively semi-circular myelinated fibers. In the diabetic control rats, the sural nerve did not exhibit any marked degenerative changes. It showed deformity (reduction in circularity) of the myelinated fibers with a decrease in their axonal and myelin areas (atrophy) when compared to the non-diabetic control rats. In the ranirestat-treated diabetic rats, the circularity of the myelinated fibers was

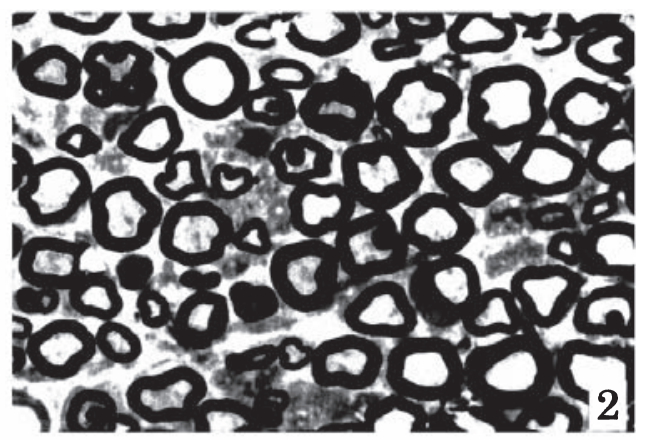

Fig. 5. Photomicrographs of transverse sections of the sural nerve from a diabetic control (1), ranirestat-treated diabetic (2), and non-diabetic control rat (3). The myelinated fibers in the diabetic control rat (1) show overt deformity (decreased circularity) with myelin and axonal atrophy. In the ranirestat-treated diabetic rat (2), the circularity of the myelinated fibers is well preserved, showing no difference from that in the non-diabetic control rat (3). Toluidine blue staining, $\times 1000$.

well preserved without any difference from the nondiabetic control rats (Fig. 5).

Morphometric analysis of the sural nerve using an image analyzer revealed that the axonal area, myelin area, myelinated fiber area, and circularity index (degree of circularity) in the diabetic control rats were significantly $(P<0.01)$ smaller than those in the non-diabetic control rats. In the ranirestat-treated rats, the decrease in these morphometric parameters was of a lesser degree when compared to the non-diabetic control animal. The axonal area, myelinated fiber area, and circularity index were significantly $(P<0.01)$ greater than in the diabetic control group. Importantly, the circularity index in the ranirestat-treated diabetic rats was almost the same as that in the non-diabetic control group (Table 2).

To investigate the preventive effects of ranirestat on

Table 2. Effects of ranirestat on morphological changes in myelinated nerve fibers in diabetic rats

\begin{tabular}{lcccc}
\hline Group & $\begin{array}{c}\text { Axonal area } \\
\left(\mu \mathrm{m}^{2}\right)\end{array}$ & $\begin{array}{c}\text { Myelin area } \\
\left(\mu \mathrm{m}^{2}\right)\end{array}$ & $\begin{array}{c}\text { Myelinated fiber area } \\
\left(\mu \mathrm{m}^{2}\right)\end{array}$ & $\begin{array}{c}\text { Circularity index } \\
\text { of myelinated fibers }\end{array}$ \\
\hline Diabetic control & $14.7 \pm 0.4^{\mathrm{b}}$ & $15.2 \pm 0.7^{\# \#}$ & $29.9 \pm 1.1^{\# \#}$ & $0.794 \pm 0.008^{\# \#}$ \\
Ranirestat-treated diabetic & $16.3 \pm 0.5^{*}$ & $19.7 \pm 0.7^{* *}$ & $35.9 \pm 1.2^{* *}$ & $0.884 \pm 0.004^{* *}$ \\
Non-diabetic control & $18.6 \pm 0.5$ & $25.5 \pm 0.5$ & $44.1 \pm 0.8$ & $0.877 \pm 0.004$ \\
\hline
\end{tabular}

Transverse sections of the sural nerve were prepared in the diabetic control, ranirestat-treated diabetic, and non-diabetic control groups. Morphometric analysis (axonal area, myelin area, and circularity index) was performed on 100 myelinated nerve fibers per rat by light microscopy. ${ }^{\text {a) }}$ The meylinated fiber area is the sum of the axonal and myelin areas. ${ }^{\text {b) }}$ The circularity index is the reciprocal of the perimeter (degree of circumferential ruggedness) of the nerve fibers, i.e., the relative value assuming the perimeter of a complete circle as 1 . Each value represents are the mean \pm S.E.M. for 13 rats/group. Comparison of two groups against the diabetic control group: $P<0.05, P<0.01$ (Student's $t$-test). Comparison of two groups against the non-diabetic control group: ${ }^{\#} P<0.01$ (Student's $t$-test). 


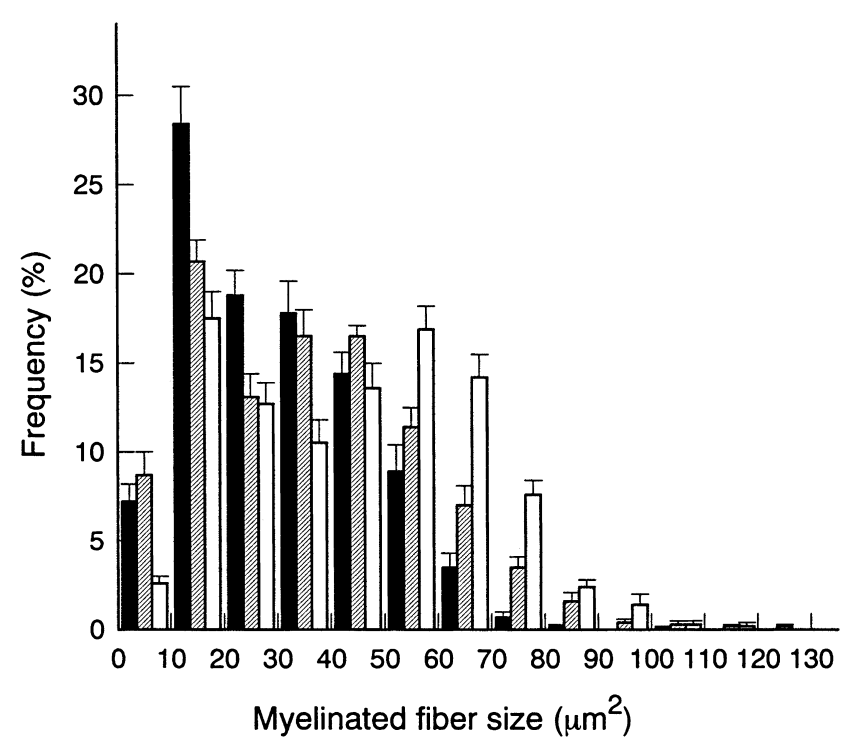

Fig. 6. Size frequency histograms of myelinated fibers of the sural nerve in diabetic control (closed column), ranirestat-treated diabetic (striped column), and non-diabetic control (open column) rats. Measured myelinated fiber areas (100 myelinated fibers/rat) were classified into 13 categories using a unit area of $10 \mu \mathrm{m}^{2}\left(0-10 \mu \mathrm{m}^{2}\right.$, etc., to $120-130 \mu \mathrm{m}^{2}$ ), and the frequency (\%) of each size was expressed as the mean \pm S.E.M. of 13 rats/group.

the STZ-induced decrease in the myelinated fiber area in more detail, the size frequency distribution of the myelinated fibers in each group was analyzed. In the non-diabetic control group, the size frequency histogram of the myelinated fibers was biphasic with two peaks at $10-20$ and $50-60 \mu \mathrm{m}^{2}$. In the diabetic control group, the number of large caliber fibers $\left(50 \mu \mathrm{m}^{2}\right.$ or more) decreased and the number of small caliber fibers $\left(10-40 \mu \mathrm{m}^{2}\right)$ increased compared to those in the nondiabetic control group (Fig. 6). In the ranirestat-treated diabetic group, the decrease in the number of large caliber fibers $\left(50 \mu \mathrm{m}^{2}\right.$ or more) was inhibited and the increase in the number of small caliber fibers $(10-40$ $\mu \mathrm{m}^{2}$ ) tended to be less as compared with those in the diabetic control group.

\section{Effects of ranirestat on the development of cataracts in rats}

The rat eyeballs were periodically examined by slit lamp throughout the study. In the diabetic control rats, lens opacities were detectable 8 weeks after the induction of diabetes. Almost all rats developed severe cataracts by 34 weeks after STZ injection. However, in the ranirestat-treated diabetic rats, generally no lens opacities were observed in any rat throughout the entire experimental period. The opacity score at 34 weeks after STZ injection was little different from that of the nondiabetic control rats (Figs. 7 and 8). In the non-diabetic control rats, no notable change in the lens opacity score was observed during the 35 weeks of the study period.

Thirty-five weeks after the start of the study, ocular tissue sections were prepared from each group and examined under the light microscope. In the diabetic control group, the lens of all rats showed typical changes such as degeneration, swelling, and disruption of lens fibers. In the ranirestat-treated diabetic group, these changes were not observed in any lens. All rats maintained lens morphology similar to that of the nondiabetic control rats (Fig. 9).

Retinal tissues from rats in each group were also examined histopathologically. All rats in the diabetic control group and ranirestat-treated diabetic groups showed normal retinal histology similar to that of the non-diabetic control rats (data not shown).
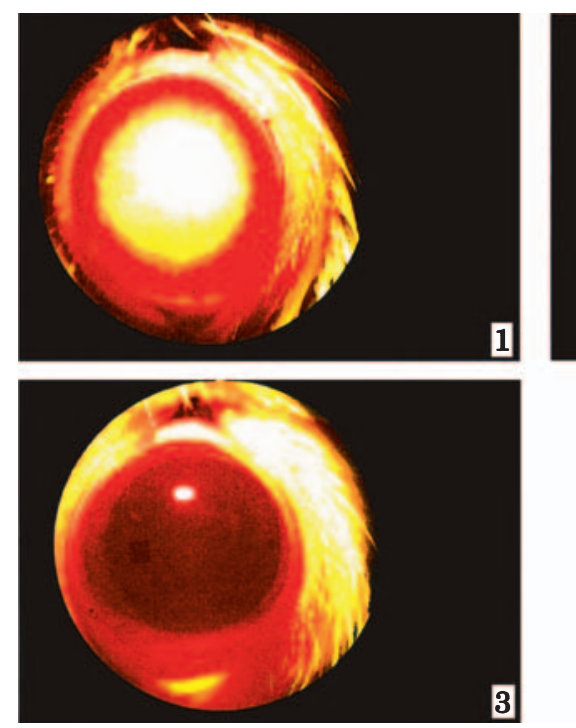

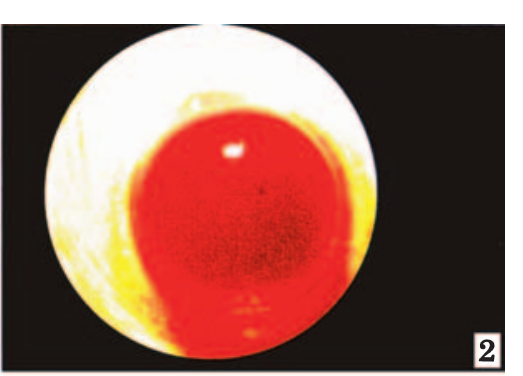

Fig. 7. Ocular photographs of a diabetic control (1), a ranirestat-treated diabetic (2), and a non-diabetic control (3) rat. In the diabetic control rat, diffuse opacities involve the entire lens, demonstrating severe cataract-like changes. As in the non-diabetic control rat (3), no lens opacities were observed in the ranirestattreated diabetic rat (2). 


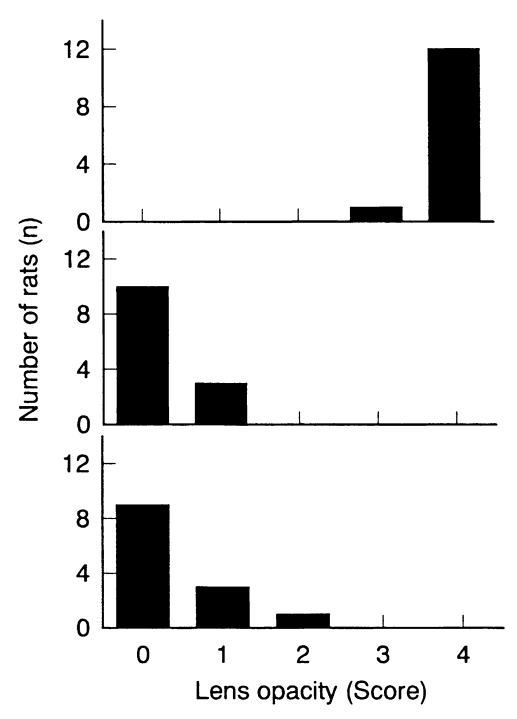

Fig. 8. Lens opacity scores in the diabetic control (upper), ranirestat-treated diabetic (middle), and non-diabetic control (lower) rats. The degree of lens opacity was scored, and the distributions of the scores of 13 rats/group are presented. $0=$ normal, $1=$ slight superficial opacity, 2 = diffuse central opacity. Cataract-like changes in each rat were scored as $0-4$ for both eyes.

\section{Discussion}

In the present study we investigated the functional and histopathological changes in the sciatic nerve and lens of STZ-diabetic rats and whether ranirestat, a potent aldose reductase inhibitor, prevents these changes. As hyperglycemia accelerated the flux of the polyol pathway, ranirestat interrupted this flux, thereby ameliorating diabetic neuropathy and preventing cataract formation.

In this study, the mean dose of ranirestat was about $0.8 \mathrm{mg} / \mathrm{kg}$ per day, which is much lower than $10 \mathrm{mg} / \mathrm{kg}$ per day, no observed adverse effect level (NOAEL) in dog studies. At this dose, we confirmed that the increased sorbitol and fructose levels in the sciatic nerve and retina were normalized (19). Ranirestat inhibited sorbitol accumulation in the sciatic nerve in STZdiabetic rats with an $\mathrm{ED}_{50}$ value about 16 times that of fidarestat, about 280 times that of zenarestat, and over 5000 times that of epalrestat (unpublished data). Our results show that rats treated with STZ exhibit significantly $(P<0.01)$ higher sorbitol contents in the sciatic nerve and lens compared to non-diabetic control rats. Treatment with ranirestat significantly $(P<0.01)$ reduced the sorbitol content in the sciatic nerve. However, ranirestat had less effect on the sorbitol levels in the lens of STZ-treated rats. In addition, treatment with ranirestat significantly $(P<0.01)$ improved the decrease in sciatic MNCV induced by pre-administration of STZ in rats. Examination of morphological and morphometric changes in the rat sural nerve revealed that treatment with STZ results in deformity (reduction in circularity) of the myelinated fibers with a decrease in their axonal and myelin areas (atrophy). Treatment with ranirestat prevented these changes. Finally, rats administered STZ developed obvious lens opacities. However, in the ranirestat-treated diabetic rats, lens opacities were not observed throughout the treatment period.

STZ-diabetic rats have been reported to show sciatic nerve and lens functional and biochemical changes similar to those that occur in patients with diabetes (17, $18,20,21)$, although the histopathological changes in STZ-induced diabetic rats are milder than functional and biochemical abnormalities (19). In addition, neuropathological lesions characterized by reduced axonal area (atrophy) of the peripheral meylinated nerve fibers have been reported in STZ-diabetic rats $(14,22,23)$. Axonal deformity (decreased circularity index) due to
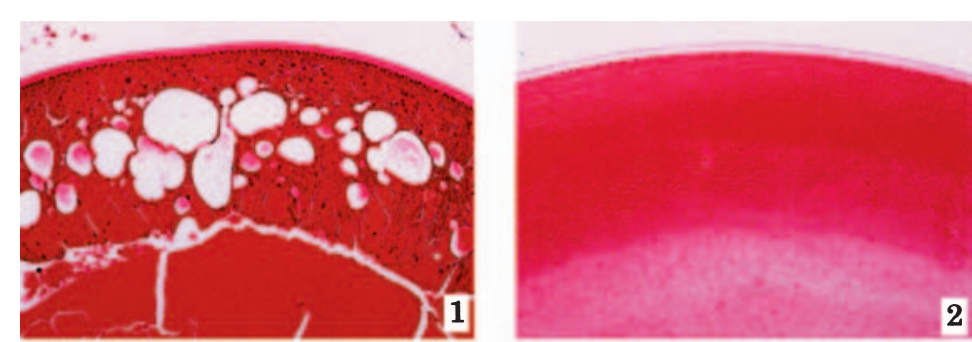

Fig. 9. Photomicrographs of lenticular tissue in a diabetic control (1), ranirestattreated diabetic (2), and non-diabetic control (3) rat. In the diabetic control rat (1), degeneration, swelling, and disruption of lens fibers are observed, indicating typical cataract-like changes. Hematoxylin-eosin staining, $\times 80$. 
axonal atrophy in STZ-induced diabetic rats has also been reported by Sugimura et al. (24). These structural abnormalities are associated with a slowing of nerve conduction velocity and reduced action potential amplitudes (25). Therefore, the results in our test systems are consistent with those previously reported.

The improvement of motor nerve function in STZinduced diabetic rats after 35 weeks of ranirestat treatment was associated with improved histopathology; that is, nerve structure improved concordant with nerve function. The atrophy and deformity of myelinated nerve fibers found in our experiments are in good agreement with the results of previous studies $(25,26)$. In the diabetic control rats in our study, sorbitol levels in the sciatic nerve were significantly $(P<0.01)$ higher than that in the non-diabetic control rats. The degree of hyperglycemia induced by STZ increased the flux of the polyol pathway with a shrinkage of the myelinated nerve fiber area. When rats were treated with ranirestat, sorbitol levels in the sciatic nerve were normalized and both atrophy and deformity of myelinated nerve fibers were prevented. Therefore normalization of nerve sorbitol is a sufficient condition to prevent diabetic neuropathy, thereby confirming the importance of the polyol pathway in the pathogenesis of neuropathy. A similar relationship between increased nerve sorbitol, atrophy, and deformity of myelinated nerve fibers has been reported previously both in animal studies and in humans $(26,27)$.

Analysis of the size frequency histogram of the myelinated fibers showed that treatment with ranirestat inhibited the decrease in the number of large fibers $\left(50 \mu \mathrm{m}^{2}\right.$ or more) and ameliorated the increase in the numbers of small fibers $\left(10-40 \mu \mathrm{m}^{2}\right)$. In this study, we found that ranirestat prevents diabetes-associated myelinated fiber atrophy. We therefore speculate that ranirestat partially supports regeneration of diabetesinduced decrease in morphometric parameters. Ranirestat was markedly effective in inhibiting the deformity of the myelinated nerve fibers and maintaining a circularity index similar to the index in non-diabetic control rats. These morphological abnormalities contribute to the impaired conduction of electrical signals in diabetic nerve $(28,29)$ and may explain the beneficial effects of ranirestat on MNCV. These findings in the diabetic animal model agree with the clinical results from a study in patients with mild-moderate diabetic sensorimotor polyneuropathy, showing that ranirestat increases nerve conduction velocity and inhibits the polyol pathway in these patients (15).

Cataract formation in STZ-diabetic rats is a common complication of poorly controlled diabetes $(30,31)$. The lens of STZ-diabetic control rats showed degeneration, swelling, and disruption of lens fibers, indicating typical cataract-like changes. Ranirestat almost completely inhibited cataract formation in the STZ-rat model. Cataract formation in STZ-diabetic rats and galactosemic rats has been well documented (32). These cataracts are thought to be induced by a series of biochemical processes such as enhanced polyol pathway metabolism, sorbitol accumulation, and increased intracellular osmolarity in the lens (22).

In our study, the reduction of accumulated sorbitol in the lens of STZ-diabetic rats was quantitatively less than that found in the sciatic nerve when studied in the same experiment. This is inconsistent with the results of a radio-autography study where $\left[{ }^{14} \mathrm{C}\right]$-labeled ranirestat was given repeatedly at $2 \mathrm{mg} / \mathrm{kg}$ per day, p.o. to rats. This radioautography study showed that ranirestat concentration in several organs is approximately the same after 3 weeks administration. In addition the ratio of ranirestat concentration in tissue and plasma is approximately the same in both the repeated and single administration of ranirestat (unpublished data). These findings indicate that ranirestat penetrates almost all tissues without specificity and potently inhibits AR. We therefore speculate that disruption of lens tissue may leak sorbitol outside the lens in STZ-diabetic rats. We believe the main point in this study regarding the effect of ranirestat on cataract is that sorbitol content in the ranirestat-treated diabetic group is lower than that in the diabetic control group. Despite this relatively low magnitude of lens sorbitol inhibition, ranirestat effectively prevented cataract development in our study, indicating that cataract formation is more sensitive to polyol pathway inhibition compared to peripheral nerve.

Finally, administration of ranirestat to STZ-diabetic rats had no effect on body weight, food consumption, or blood glucose when compared to diabetic controls, so the findings cannot be explained by differences in glycemic control.

In summary, the beneficial effects of ranirestat on the morphological and functional changes induced by treatment with STZ in rats were accompanied by inhibition of sorbitol accumulation in both the sciatic nerve and lens. These findings indicate that the polyol pathway plays an important role in the development of diabetic neuropathy and cataracts in STZ-treated diabetic rats. Ranirestat could be a promising agent for the treatment of the microvascular complications associated with diabetes, particularly neuropathy.

\section{References}

1 Lorenzi M. The polyol pathway as a mechanism for diabetic retinopathy: attractive, elusive, and resilient. Exp Diabetes Res. 
2007;2007:61038.

2 Suzen S, Buyukbingol E. Recent studies of aldose reductase enzyme inhibition for diabetic complications. Curr Med Chem. 2003;10:1329-1352.

3 Oates PJ. Aldose reductase, still a compelling target for diabetic neuropathy. Curr Drug Targets. 2008;9:14-36

4 Perkins BA, Bril V. Emerging therapies for diabetic neuropathy: a clinical overview. Curr Diabetes Rev. 2005;1:271-280.

5 Várkonyi T, Kempler P. Diabetic neuropathy: new strategies for treatment. Diabetes Obes Metab. 2008;10:99-108.

6 Kametaka S, Kasahara T, Ueo M, Takenaka M, Saito M, Sakamoto $\mathrm{K}$, et al. A novel high resolution in vivo digital imaging system for the evaluation of experimental cataract in diabetic rats. J Pharmacol Sci. 2008;106:144-151.

7 Zatechka DS Jr, Kador PF, Garcia-Castiñeiras S, Lou MF. Diabetes can alter the signal transduction pathways in the lens of rats. Diabetes. 2003;52:1014-1022.

8 LinksRicheti F, Noronha RM, Waetge RT, de Vasconcellos JP, de Souza OF, Kneipp B, et al. Evaluation of AC(n) and $\mathrm{C}(-106) \mathrm{T}$ polymorphisms of the aldose reductase gene in Brazilian patients with DM1 and susceptibility to diabetic retinopathy. Mol Vis. 2007;23:740-745.

9 Bloomgarden ZT. Screening for and managing diabetic retinopathy: current approaches. Am J Health Syst Pharm. 2007;64: S8-S14.

10 Schrijvers BF, De Vriese AS. Novel insights in the treatment of diabetic nephropathy. Acta Clin Belg. 2007;62:278-290.

11 Ii S, Ohta M, Kudo E, Yamaoka T, Tachikawa T, Moritani M, et al. Redox state-dependent and sorbitol accumulationindependent diabetic albuminuria in mice with transgenederived human aldose reductase and sorbitol dehydrogenase deficiency. Diabetologia. 2004;47:541-548.

12 Matsuoka K, Sakamoto N, Akanuma Y, Hotta N, Shichiri M, Toyota $\mathrm{T}$, et al. A long-term effect of epalrestat on motor conduction velocity of diabetic patients: ARI-Diabetes Complications Trial (ADCT). Diabetes Res Clin Pract. 2007;77: S263-S268.

13 Brown MJ, Bird SJ, Watling S, Kaleta H, Hayes L, Eckert S, et al. Natural progression of diabetic peripheral neuropathy in the Zenarestat study population. Diabetes Care. 2004;27:11531159.

14 Hotta N, Yasuda K, Sumita Y, Sano T, Kakuta H, Nagashima M, et al. Effects of a novel aldose reductase inhibitor, fidarestat (SNK-860), on vibration perception threshold and subjective symptoms in patients with diabetic polyneuropathy: an openlabel pilot study. Clin Drug Investig. 2004;24:671-680.

15 Bril V, Buchanan RA. Long-term effects of ranirestat (AS-3201) on peripheral nerve function in patients with diabetic sensorimotor polyneuropathy. Diabetes Care. 2006;29:68-72.

16 Clements RS Jr, Morrison AD, Winegrad AI. Polyol pathway in aorta: regulation by hormones. Science. 1969;166:1007-1008.

17 Sharma AK, Thomas PK. Peripheral nerve structure and function in experimental diabetes. J Neurol Sci. 1974;23:1-15.

18 Ao S, Shingu Y, Kikuchi C, Takano Y, Nomura K, Fujiwara T, et al. Characterization of a novel aldose reductase inhibitor, FR74366, and its effects on diabetic cataract and neuropathy in the rat. Metabolism. 1991;40:77-87.

19 Matsumoto T, Ono Y, Kurono M, Kuromiya A, Nakamura K,
Bril V. Ranirestat (AS-3201), a potent aldose reductase inhibitor, reduces sorbitol levels and improves motor nerve conduction velocity in streptozotocin-diabetic rats. J Pharmacol Sci. 2008; 107:231-237.

20 Sharma AK, Thomas PK. Animal models: pathologyand pathophysiology. In: Dyck PJ, Thomas PK, Ashbury AK, Winegrad AL, Porte D Jr, editors. Diabetic neuropathy. Philadelphia: Saunders; 1987. p. 237-252.

21 Ashizawa N, Yoshida M, Sugiyama Y, Akaike N, Ohbayashi S, Aotsuka $\mathrm{T}$, et al. Effects of a novel potent aldose reductase inhibitor, GP-1447, on aldose reductase activity in vitro and on diabetic neuropathy and cataract formation in rats. Jpn J Pharmacol. 1997;73:133-144.

22 Cameron NE, Leonard MB, Ross IS, Whiting PH. The effects of sorbinil on peripheral nerve conduction velocity, polyol concentrations and morphology in the streptozotocin-diabetic rat. Diabetologia. 1986;29:168-174.

23 Yagihashi S, Kamijo M, Ido Y, Mirrlees DJ. Effects of longterm aldose reductase inhibition on development of experimental diabetic neuropathy. Ultrastructural and morphometric studies of sural nerve in streptozocin-induced diabetic rats. Diabetes. 1990;39:690-696.

24 Sugimura K, Windebank AJ, Natarajan V, Lambert EH, Schmid HH, Dyck PJ. Interstitial hyperosmolarity may cause axis cylinder shrinkage in streptozotocin diabetic nerve. J Neuropathol Exp Neurol. 1980;39:710-721.

25 Qiang X, Satoh J, Sagara M, Fukuzawa M, Masuda T, Sakata Y. Inhibitory effect of troglitazone on diabetic neuropathy in streptozotocin-induced diabetic rats. Diabetologia. 1998;41: 1321-1326.

26 Kato N, Mizuno K, Makino M, Suzuki T, Yagihashi S. Effects of 15-month aldose reductase inhibition with fidarestat on the experimental diabetic neuropathy in rats. Diabetes Res Clin Pract. 2000;50:77-85.

27 Kamijo M, Basso M, Cherian PV, Hohman TC, Sima AA. Galactosemia produces ARI-preventable nodal changes similar to those of diabetic neuropathy. Diabetes Res Clin Pract. 1994;25:117-129.

28 Waxman SG. Determinants of conduction velocity in myelinated nerve fibers. Muscle Nerve. 1980;3:141-150.

29 Greene DA, Arezzo JC, Brown MB. Effect of aldose reductase inhibition on nerve conduction and morphometry in diabetic neuropathy. Zenarestat Study Group. Neurology. 1999;53:580 591.

30 Clark TA, Heyliger CE, Edel AL, Goel DP, Pierce GN. Codelivery of a tea extract prevents morbidity and mortality associated with oral vanadate therapy in streptozotocin-induced diabetic rats. Metabolism. 2004;53:1145-1151.

31 Kador PF, Randazzo J, Babb T, Koushik K, Takamura Y, Zhu $\mathrm{W}$, et al. Topical aldose reductase inhibitor formulations for effective lens drug delivery in a rat model for sugar cataracts. J Ocul Pharmacol Ther. 2007;23:116-123.

32 Aukunuru JV, Sunkara G, Ayalasomayajula SP, DeRuiter J, Clark RC, Kompella UB. A biodegradable injectable implant sustains systemic and ocular delivery of an aldose reductase inhibitor and ameliorates biochemical changes in a galactose-fed rat model for diabetic complications. Pharm Res. 2002;19:278285 . 